\title{
E agora, minha gente, uma história eu vou contar: experiências de formação de leitores no berçário
}

\author{
And now, my people, a story I'm going to tell you: training experiences for readers in the nursery
}

\section{Caroline Rodrigues Melo \\ Zila Letícia Pereira Rêgo}

Universidade Federal do Pampa - UNIPAMPA - Bagé - Rio Grande do Sul - Brasil

\begin{abstract}
Resumo: $O$ presente artigo relata procedimentos e resultados alcançados com projetos de leitura literária desenvolvidos em turmas de berçário I e II de uma escola particular de Educação Infantil de Bagé/RS durante nove meses do ano de 2017. A questão norteadora da investigação foi analisar a interação entre crianças e livros, avaliando em que medida as ações corroboraram a construção de um comportamento leitor por parte dos pequenos alunos. Nesse sentido, descrevemos e analisamos três projetos de leitura ( $E u$ conto, tu recontas, nós nos encantamos, Cantinho do Era uma vez... e Sacola Viajante) aplicados nas turmas, considerando conceitos e pressupostos teóricos advindos da educação e da teoria literária. Os resultados obtidos nos levam a concluir que projetos de literatura em turmas de berçário propiciam a aproximação aos livros e contribuem para a formação de hábitos leitores, mas que a intenção pedagógica e o engajamento familiar são determinantes na sua concretização.
\end{abstract}

Palavras-chave: Educação infantil. Berçário. Formação de leitores. Projetos de leitura literária.

\begin{abstract}
This article reports on procedures and results achieved with literary reading projects developed in nursery classes I and II of a private nursery school in Bagé / RS during nine months of the year 2017. The guiding question of the research was to analyze the interaction between children and books, evaluating the extent to which the actions corroborated the construction of a reading behavior by the small students. In this sense, we describe and analyze three reading projects (I count, you recount, we enchanted ourselves, Place of once ... and Traveling Bag) applied in the classes, considering concepts and theoretical presuppositions derived from education and literary theory. The results obtained lead us to conclude that literature projects in nursery classes lead to the approach to books and contribute to the formation of reading habits, but that the pedagogical intention and the family engagement are determinant in its concretization.
\end{abstract}

Key words: Child education. Nursery. Training of readers. Literary reading projects. 


\section{Introdução}

O presente artigo aborda os resultados alcançados pela pesquisa $E$ agora, minha gente, uma história eu vou contar: experiências de formação de leitores no berçário, que analisou as interações entre obras literárias e leitores propiciadas por práticas pedagógicas desenvolvidas em turmas de Berçário I e II. A questão que norteou a investigação foi refletir em que medida propostas pedagógicas que contemplam leitura literária em turmas de berçário permitem a aproximação entre crianças e livros, considerando se tais atividades corroboram a formação leitora desses alunos.

Nossa pesquisa se justifica pelo fato de que, para algumas crianças, o único lugar no qual há acesso aos livros é a escola, sendo o professor o mediador natural dessa primeira experiência literária. Entendemos que as escolas de Educação Infantil precisam assumir o papel de formadoras de leitores, incentivando a leitura literária em suas atividades diárias, pois para os alunos que ingressam nessas instituições, em específico em turmas de berçário, esse representa o primeiro contato com o ambiente escolar e, muitas vezes, com a literatura também.

Sabemos que a leitura literária na infância traz inúmeros benefícios, como o enriquecimento da imaginação, o desenvolvimento da atenção, o estímulo à curiosidade e à criatividade, a ampliação do vocabulário, a descoberta de novos conhecimentos, entre outros. Ainda que as crianças bem pequenas, como as que foram envolvidas com os projetos, não leiam de forma convencional, ou seja, não decodifiquem palavras escritas, elas realizam a leitura de imagem e criam histórias a seu modo. Consequentemente, cercá-las de práticas em que a literatura se faça presente é significativo para sua formação como um todo.

Considerando isso, é indispensável que os docentes se comprometam em elaborar práticas pedagógicas que auxiliem o início da caminhada leitora das crianças, assumindo o importante papel de facilitador na relação entre os livros e os alunos. Em razão da pouca idade, posto que as escolas de
Educação Infantil recebem discentes a partir dos quatro meses, o professor se torna essencial para que tal interação aconteça, sendo ele geralmente o mediador natural desse processo no contexto escolar. Por outro lado, o papel da família como animadora da leitura é igualmente importante, pois as crianças pequenas necessitam desse auxílio para chegar até os livros. Mesmo que as ações que incentivem e promovam a leitura literária sejam fomentadas na escola, elas precisam contar com a colaboração familiar para que haja a continuidade desse trabalho para além da escolarização. Por essa razão, esta pesquisa também envolveu atividades e registros que contaram com as famílias no desenvolvimento dos projetos.

O público para o qual foram destinadas as ações pertence a famílias de classe média alta, o que nos levou a supor que essas crianças teriam mais acesso a bens culturais tangíveis e intangíveis. A pesquisa Retratos da Leitura no Brasil ${ }^{1}$ menciona que "Em geral, quanto maior a escolaridade e a classe, maior a proporção de compradores de livros. No entanto, chama atenção que cerca de metade dos estudantes e metade dos leitores não são compradores de livros". Logo, embora tal fator possa desencadear a aquisição de livros, isso não é garantia de que os pequenos tenham esse contato estimulado e mediado, nem que se tornem leitores. Daí a importância de a escola promover ações integradas nesse sentido.

A referida pesquisa ainda indica que $11 \%$ dos entrevistados relatam que a mãe ou responsável do sexo feminino foi uma figura de influência para o desenvolvimento do gosto por ler; em seguida, com $9 \%$, são citados os professores. Dessa forma, presumimos que, mesmo pertencendo a uma classe social mais favorecida, esses alunos necessitam de um ambiente, de práticas e de mediadores que favoreçam a constituição e o desenvolvimento de sua

\footnotetext{
${ }^{1}$ Pesquisa realizada pelo Instituto Pró-Livro no Brasil entre 23 de novembro a 14 de dezembro de 2015 e publicada em 2016 . Disponível em:

<http://prolivro.org.br/home/images/2016/Pesquisa_Retratos_da _Leitura_no_Brasil_-_2015.pdf.>. Acesso em 05 de abril de 2017.
} 
formação leitora, o que a pesquisa aqui apresentada procurou, enfim, promover e analisar.

\section{Desenvolvimento}

A Educação Infantil configura-se como a primeira etapa da educação básica e, segundo o artigo 29 da Lei de Diretrizes e Bases da Educação Nacional (Lei 9.394, de 1996), tem como finalidade "o desenvolvimento integral da criança de até 5 (cinco) anos, em seus aspectos físico, psicológico, intelectual e social, complementando a ação da família e da comunidade". Percebemos o importante papel que essa etapa possui no desenvolvimento da criança e, deste modo, os profissionais envolvidos nesse processo precisam se preocupar com diversos aspectos relacionados à formação e aprendizagem dos alunos. Trata-se de um nível de ensino em que os alunos estabelecerão seus primeiros contatos como ouvintes de histórias mediante atividades que exploram a oralidade, fomentando 0 seu desenvolvimento.

Essas ações são significativas para favorecer a formação de leitores na Educação Infantil, uma vez que a presença da Literatura Infantil no ambiente escolar de crianças pequenas desperta sua curiosidade e envolvimento em tais atividades. Dentre essas intervenções literárias, destacamos a de contação de histórias, responsável por momentos de interação, impulsionando o uso da ludicidade e a construção de novos saberes, além de propiciar a troca de conhecimentos entre os alunos e o professor. Essa proposta se destaca também pela variedade de abordagens que oferece, assim como pela multiplicidade de significados que o trabalho com a leitura literária permite, como, por exemplo, a integração e a socialização, a promoção da oralidade e, igualmente, a abertura de caminhos para a aquisição da escrita.

Na concepção de Vigotski (2014, p. 35-36), "A infância é considerada como sendo o período em que mais se desenvolve a fantasia e, de acordo com esse critério, à medida que a criança se desenvolve, a sua capacidade imaginativa e as suas fantasias começam a diminuir". Logo, nessa fase, as atividades escolares que privilegiam a ludicidade, o brincar, a fantasia e o faz de conta são imprescindíveis para o desenvolvimento do imaginário. Do mesmo modo, Vigotski ressalta o papel da imaginação na constituição humana:

[...] a imaginação adquire uma função muito importante no comportamento e desenvolvimento humanos, transforma-se em meio para ampliar a experiência do homem porque, desse modo, este poderá imaginar aquilo que nunca viu, poderá a partir da descrição do outro representar para si também a descrição daquilo que na sua própria experiência pessoal não existiu, o que não está limitado pelo círculo e fronteiras estritas da sua própria experiência, mas pode também ir além das suas fronteiras, assimilando com a ajuda da imaginação, a experiência histórica e social de outros. Sob essa forma, a imaginação é condição absolutamente necessária de quase toda a atividade intelectual do homem (2014, p. 15).

Essa mesma ideia é apresentada por Mir (2004, p. 39) quando afirma que a experiência com objetos e com o meio no qual o infante está relacionado é essencial, pois "está relacionada ao desenvolvimento afetivo e cognitivo. Constituirá uma das condutas instrumentais básicas para a adaptação da criança ao meio e à descoberta e estruturação do espaço". Logo, a exploração visual e tátil são primordiais para a aprendizagem porque, partindo delas, serão construídas conexões com aquilo que é exterior à criança, para que assim seja estabelecida a comunicação e a interação com o meio.

Por outro lado, se a função da família e da escola na formação dos novos leitores é inquestionável, ela se dá de forma específica, com ingredientes próprios da relação que a criança mantém com pais/irmãos/familiares ou com professores e colegas. Embora distintas, essa relação precisa ser entendida como complementar, onde escola depende da família e vice-versa. Muitas crianças chegam às escolas de Educação Infantil aos quatro meses e, portanto, o ambiente escolar também passa a integrar o meio responsável por proporcionar estímulos adequados para seu desenvolvimento enquanto sujeitos, englobando o seu progresso nos 
aspectos físico, motor, intelectual, afetivo, emocional e social.

Sendo assim, pensar na formação de leitores na Educação Infantil significa considerar vários fatores: a criança, a escola, o ambiente de sala de aula, os professores e profissionais que estão envolvidos no processo de ensino-aprendizagem, as atividades por eles desenvolvidas e o acervo disponível. Em alguns casos, os primeiros contatos entre essas crianças e os livros acontecem em sala de aula pela mediação dos professores, portanto o hábito de leitura acaba sendo construído na escola, sendo esse um dos acessos ao mundo letrado. Nessa perspectiva, Debus afirma que:

Quando a criança pequena passa os dedos levemente na letra encerrada numa página ou na imagem colorida estampada no livro e tenta construir hipóteses de sentido através desse exercício, ela está se apropriando de uma leitura específica para aquele momento, a sua leitura imaginária/ficcional/de "mentirinha", mas sua. O professor, ao inserila nas práticas sociais de leitura - ir à biblioteca, ler em voz alta, contar histórias -, está mediando o processo e contribuindo com a inserção e permanência dela nesse mundo letrado (2006, p. 19).

A literatura suscita no leitor a possibilidade de descobrir novos lugares, conhecimentos, mobilizando sentimentos e emoções. Os aspectos afetivos e simbólicos oportunizados pelo contato com livros são significativos para as crianças na faixa etária de quatro meses a dois anos, pois elas buscam identificação com as narrativas e, por vezes, reproduzem em suas interações sociais as vivências obtidas com a leitura. São igualmente instigadas a criticidade e a sensibilidade, propiciando a humanização através da interação com os livros.

Em vista disso, considerar as necessidades e singularidades da criança é importante para escolher as obras que serão apresentadas para esse público, sendo inicialmente necessário ofertar livros de materiais mais resistentes, como E.V.A, tecido, papelão, entre outros, a fim de que os alunos iniciem esse contato com o objeto livro. Hunt (2010, p. 93) afirma que "[...] a relação entre a criança - isto é, o leitor em desenvolvimento - e o texto é complexa e tem implicações no modo como discutimos, lecionamos e escolhemos materiais". Desta maneira, o acervo ofertado aos alunos da Educação Infantil precisa contemplar livros de diferentes gêneros, formas e materiais, dado que o livro será inicialmente um objeto, um brinquedo a ser manipulado e explorado de todas as maneiras possíveis.

O primeiro contato da criança com o universo literário acontece, inicialmente, através da literatura oral, muitas vezes ainda no contexto familiar. As cantigas e os acalantos são também uma forma de ligar e apresentar os pequenos a sua cultura, possibilitando o desenvolvimento da oralidade e da criticidade, estimulado a imaginação e a criatividade, além de inseri-los de forma lúdica e prazerosa no mundo literário. Bordini acrescenta que

A função da poesia, bem como da arte literária em geral, não é aperfeiçoar o domínio da linguagem, mas, por meio da linguagem, permitir ao sujeito um distanciamento crítico da realidade que ela the apresenta à consciência (2010, p. 97, grifo da autora).

Desse modo, o contato com a literatura ainda na escola infantil torna-se extremamente importante para promover não só a aquisição e aperfeiçoamento da linguagem, mas também para formá-la de modo mais amplo, sensível e humano.

Tendo como referência esse cenário, a proposta aqui relatada contemplou três projetos de leitura aplicados a turmas Berçário I e II (a contação de histórias $E u$ conto, tu recontas, nós nos encantamos, o cantinho do Era uma vez... e o Sacola viajante), durante nove meses do ano letivo de 2017 em uma escola particular de Educação Infantil de Bagé/RS. A seguir, apresentaremos as ações e discutiremos os resultados alcançados.

\section{Eu conto, tu recontas, nós nos encantamos: o projeto de contação de histórias em sala de aula}

O projeto de contação de histórias Eu conto, tu recontas, nós nos encantamos ocorreu na turma de Berçário II diariamente e abrangeu doze alunos com faixa etária entre um e dois anos. As obras selecionadas contemplaram diferentes temáticas e 
gêneros, sendo destinada para cada mês a abordagem de um eixo temático diferente (animais, famíia...). Foram mobilizados livros de materiais e formatos diversos: de tecido ou de E.V.A; com abas ou na forma de fantoches; livros imagens ou que contavam com recursos sonoros e sensoriais. Além disso, utilizamos diferentes recursos para as contações, como fantoches, dedoches, caixa teatro, livro cenário, avental, entre outros. Salientamos que algumas dessas obras se repetiram em outros eixos, como, por exemplo, no que abordou poesia, assim como nem todos os títulos utilizados no decorrer dos três projetos foram selecionados no início dos mesmos, pois contávamos com os livros disponíveis na escola, outros advindos do acervo pessoal das professoras do Berçário II, bem como alguns empréstimos da biblioteca do $\mathrm{NULI}^{2}$. Para selecionar as obras, foram consideradas as especificidades dos leitores para os quais se destinaram as contações, priorizando livros ricos em ilustrações e com temas próximos aos alunos e a sua faixa etária: o cotidiano infantil, os medos, as brincadeiras e brinquedos comuns a tal idade, as relações familiares, a relação com os colegas e seus conflitos, entre outros.

Alguns dos títulos escolhidos foram: 0 ratinho (Smith, 2008); O pato Piteco (Cuthbert, 2008); Por favor, sr. Panda (Antony, 2014); Tatu-balão (Barros, 2014); E o dente ainda doía (Terra, 2012); 0 elefante que queria ser diferente (Elliot, 2013); Gato pra cá, rato pra lá (Orthof, 2012); Confidências de um jacaré (Nucci, 2008); Menina bonita do laço de fita (Machado, 2001); Os hipopótamos vivem em casas? (Butterfield, 2014); Olá, selva! (Everitt-Stewart, 2014); Um homem, um menino e um burro (Burrows, 2012); Por favor, dême um abraço! (Rowe, 2011); A descoberta de joaninha (Cordeiro, 2009); Zuza, a zebra: um livro pop-up! (Gray, 2011), entre outros.

Nas primeiras contações, tentamos selecionar livros em material mais resistente, possibilitando a exploração desse objeto pelos alunos, com sequência

\footnotetext{
2 O Núcleo de Formação do Leitor Literário - NULI desenvolve projetos e ações de mediação de leitura através de metodologias de abordagem ao texto literário desenvolvidas no âmbito do Curso de Letras - Português e Literaturas de Língua Portuguesa e do Mestrado Profissional em Ensino de Línguas.
}

narrativa linear e estruturas linguísticas simples, dando ênfase para as ilustrações, pois foi o primeiro contato, em sala de aula, das crianças com aquele tipo de atividade e também porque seu grau de concentração é menor, característica pertinente à faixa etária. Foram mobilizados nesse projeto, em seus diferentes eixos, narrativas e poesias: fábulas, contos clássicos, trava-línguas, parlendas, lendas, livro imagem, poemas infantis, entre outros. Por meio de tais práticas, procuramos promover o estímulo, a participação e a oralidade das crianças, pois estavam em processo de aquisição da linguagem, sendo essencial cercá-las de atividades que propiciassem o desenvolvimento e ampliação do seu repertório oral.

\section{O cantinho do Era uma vez...}

O cantinho do Era uma vez... consistiu num painel, em TNT, com dois grandes bolsos, fixado na parede da sala dos alunos do Berçário II, e que continha um acervo de livros feitos com diferentes materiais, entre eles, livros de tecido, de banho e de material resistente. Esse painel ficou disponível aos pequenos de março até dezembro e foi colocado numa altura acessível, possibilitando o livre acesso às obras que, por sua vez, foram renovadas quinzenalmente. Tal espaço também era próximo ao tapete, facilitando a acomodação dos alunos nos possíveis momentos de manuseio e exploração do objeto livro.

Dentre os livros disponibilizados no painel, estão os seguintes: Animais da fazenda (Ferri, 2012); Uma linda borboleta (Vale das Letras, 2011); Livro de pano do bebê: descansar (Silveira, 2012); Rex, o cãozinho (Belli, 2009); 0 suricato mais medroso do deserto (Castro, 2014); Meg, a gatinha: dia feliz (Jones, 2005); Gatinho (Belli, 2013); Quando estou triste (Spelman, 2003); Popi, o camelo (Smith, 2005), entre outros.

Inicialmente, foi necessária a mediação para direcionar em quais momentos os livros poderiam ser manipulados, pois os alunos queriam acessá-los durante outras atividades. Nos primeiros dias, por diversas vezes, o combinado precisou ser reforçado, 
pois os livros eram jogados no chão da sala de aula e os pequenos se dispersavam rapidamente. No entanto, no segundo semestre letivo, foi estabelecido o hábito dos alunos de retirarem o livro, sentarem-se no tapete ou nas mesas, cantarem a música que rotineiramente cantavam antes das contações de histórias, lê-lo e devolvê-lo ao painel ou mesmo trocarem-nos entre os colegas. Por vezes, os alunos escolhiam aqueles que elegiam como seus "livros favoritos" e solicitavam que fizéssemos a contação a partir deles. Observamos que a construção dessa atitude das crianças com os livros foi sendo adotada gradativamente ao longo do primeiro semestre letivo e se consolidando a partir do segundo, fazendo com que a mediação fosse sendo menos necessária.

\section{A Sacola Viajante}

O projeto Sacola Viajante consistiu em encaminhar para a casa dos alunos do Berçário I e II uma sacola de tecido, contendo acervo de três livros de Literatura Infantil selecionados pelas professoras do Berçário II, e um caderno para as famílias dos pequenos registrarem anotações referentes às reações das crianças e às circunstâncias que envolveram as contações das obras em casa. A sacola foi enviada a cada sexta-feira e devia retornar à escola na segunda-feira seguinte, sendo que o aluno que a levasse era determinado pela ordem alfabética.

A apresentação desse projeto foi feita às famílias em março, durante a primeira reunião geral de pais organizada pela escola. Nessa oportunidade, as professoras do Berçário II expuseram aos pais o intuito do projeto e a dinâmica do mesmo. Além dos livros e do caderno, a sacola também continha um bilhete com instruções para as famílias, explicando o objetivo do projeto, mencionando a data em que eles deveriam retornar com a sacola para a escola e detalhando como poderiam ser feitos os registros no caderno. Estes deveriam conter detalhes da interação da criança e da família com os livros, bem como a forma com que foi feita a contação: se havia interesse ou não da criança pelos livros, se ela havia demonstrado gostar ou não da atividade ou outras informações que a família julgasse pertinente relatar.

Também foi solicitado que houvesse, juntamente com o relato escrito, uma foto do momento da contação com intuito de ser exibida aos demais colegas. Assim que a sacola retornava à escola, o registro da interação que ocorreu em casa era apresentado ao grupo, pois, por se tratarem de crianças bem pequenas, o recurso visual auxiliava na conquista da atenção durante o momento de trazer o relato. Participaram dessa proposta quinze alunos com faixa etária entre quatro meses e dois anos.

Entre os objetivos dessa atividade estavam proporcionar aos alunos do Berçário I e II um momento de leitura literária no contexto familiar, possibilitando que a família também assumisse o papel de mediadora, complementando as ações que já estavam sendo desenvolvidas na escola. Foram feitas duas rodadas do projeto, ou seja, cada aluno recebeu a Sacola Viajante em duas oportunidades, sendo a primeira etapa realizada de 24 de março a 01 de julho de 2017. Nesse primeiro momento, foram selecionadas três narrativas, duas delas com a temática "animais" e outra abordando "relação familiar". Essa seleção foi feita, considerando as percepções que as professoras da turma do Berçário Il tinham sobre o interesse dos alunos pelo tema animais. Já a temática familiar foi escolhida pelo fato de os pequenos questionarem onde estavam os pais, pois para muitos alunos a entrada na escola era marcada pela primeira vez em que eles se distanciavam da família. Foram elas: 0 cachorro diz... au-au! (The Clever Factory, Inc., 2015), Os hipopótamos vivem em casas? (Butterfield, 2014) e Quando o papai não está em casa... (Pin, 2011).

$\mathrm{Na}$ segunda rodada, que se iniciou em 07 de julho e terminou em 16 de outubro de 2017, o acervo enviado foi composto por poesia, contendo os livros Bamboletras (Camargo, 1998), No mundo da lua (Murray, 2011) e Tatu-balão (Barros, 2014). A escolha dessas obras se deu pelo fato de abordarem, através da poesia, temas que agradam aos pequenos e fazem referência ao cotidiano infantil de forma lúdica, como as brincadeiras infantis, os brinquedos, 
os animais e a natureza, além de conterem inúmeras ilustrações.

Ao analisarmos os procedimentos adotados na aplicação dos projetos e os resultados obtidos, constatamos que, para o momento das contações, era necessário um ambiente tranquilo e sem interrupções externas. Percebemos também que no primeiro mês os alunos estavam dispersos no momento de ouvir histórias, ficando apenas por breves períodos sentados, o que acarretava na conclusão da contação antes do término das narrativas. Havia também disputa pelo livro, pois todos queriam manuseá-lo. O acesso ao cantinho do Era uma vez... também era conflituoso, no início, tendo em vista que todos queriam retirar o acervo ao mesmo tempo e que, muitas vezes, deixavam os livros espalhados pelo chão da sala ou corriam segurando-os, mas não se sentavam para manusear e explorar o material. O cuidado com o acervo era pequeno, eles puxavam e/ou mordiam as páginas, chegando por vezes a danificar alguns.

Foram necessárias muitas conversas, nos primeiros dois meses, sobre como os pequenos deveriam proceder em relação ao cantinho, ressaltando a importância do cuidado com os livros, mediando os conflitos e argumentando sobre a importância de compartilhar o acervo com os colegas. Eram igualmente reforçadas as combinações sobre 0 momento em que eles poderiam retirar os livros e onde poderiam manuseá-los. Gradativamente, notamos que os alunos começaram a adotar um novo comportamento no cantinho e durante as contações: a organização para esse momento começou a se dar mais rapidamente, pois assim que começavam cantar a música de "abertura" da atividade, eles se acomodavam no tapete. Quando retiravam livros do painel, dirigiam-se para a mesa ou tapete para manuseá-los, ainda que alguns não guardassem a obra no painel depois da interação. Outra mudança percebida foi o fato de começarem a trazer livros de casa para a leitura, sem que isso fosse solicitado. Nos últimos meses dos projetos, eles já se organizavam sem auxílio para manusear os livros do cantinho do Era uma vez..., cantando a música, sentando-se, geralmente no tapete, e convocando os demais colegas para que eles fizessem a contação. Outra conduta observada foi o fato de quererem contar histórias para os pais na hora da saída, levando os livros para a porta da sala de aula.

O caderno do Sacola Viajante, onde as famílias faziam seus registros, foi utilizado durante as duas rodadas do projeto, configurando-se em parte essencial na atividade, uma vez que algumas famílias relatavam que os filhos se interessavam em observar as imagens das interações dos demais colegas. Eles também se empolgavam ao mostrar seu relato à turma quando a sacola retornava para a escola, compartilhando, geralmente no momento da rodinha ${ }^{3}$, suas fotos e tentando relatar quem havia feito a contação em casa. Habitualmente, a professora procedia à leitura do que os pais haviam registrado com o auxílio da criança, que apontava e dava sua perspectiva.

Após observarmos os relatos das famílias, na primeira e segunda rodada do projeto, notamos que algumas fizeram registros da empolgação das crianças ao levarem a sacola para casa. A maioria optou por propor a leitura no sábado pela manhã, outras fizeram-na na noite de sexta-feira. Boa parte dos pais deixavam a criança explorar o acervo, mexer e brincar com os livros. Durante a contação, a maior parte realizada pelas mães e com os pais auxiliando com os registros (fotográfico e escrito), foi relatado que os pequenos manifestaram interesse pelas imagens, imitando os sons dos animais e reconhecendo-os. Os que tinham irmãos compartilharam essa atividade com eles. Após determinado período envolvidos nessa tarefa, as famílias relatavam que as crianças começavam a se dispersar, sendo que os pais dos alunos do Berçário I apontaram tal fato mais frequentemente. Outro dado mencionado era a curiosidade dos petizes pelo

\footnotetext{
${ }^{3}$ A hora da rodinha era adotada por todas as turmas da escola em que foram ambientados os projetos. Esse período da rotina escolar é comumente destinado para compartilhar informações do cotidiano dos alunos, onde eles mostram objetos trazidos de casa, contam fatos sobre eles e conversam com os colegas e professoras. Nesse momento, também é feita a acolhida, bem como a exposição, pelas regentes, das atividades que serão realizadas naquela tarde, uma vez que no berçário ela é a primeira atividade desenvolvida. Geralmente, são cantadas músicas para dar boa tarde e realizar a chamadinha.
} 
caderno que acompanhava a sacola, uma vez que queriam ver os registros feitos anteriormente pelos colegas, reconhecendo-os, mostrando-os e verbalizando os nomes dos amigos para os pais.

Percebemos nos relatos de certas famílias o entendimento de que aquele primeiro contato com a leitura era significativo para a criança, assim como o projeto Sacola Viajante. Além de um momento de leitura, era um momento que possibilitava a troca de informações e o convívio em família. Os pais também mencionavam que o contato com os livros acontecia mais de uma vez depois da contação, ou seja, eles acessavam o acervo em outros momentos do final de semana.

Em relação ao cumprimento dos prazos, tivemos na segunda rodada um número maior de atrasos na devolução da sacola. O número de alunos participantes no projeto Sacola Viajante foi o mesmo em ambas as rodadas, quinze alunos. O percentual de famílias que completou todas as solicitações foi de $87 \%$ na primeira rodada e de $53,33 \%$ na segunda, ou seja, houve uma diminuição. A mesma porcentagem, em ambas as rodadas, 13,33\%, realizou apenas o relato escrito. Nenhuma família fez apenas o registro fotográfico. Na primeira rodada nenhuma família deixou de fazer o registro, já na segunda, houve $33,33 \%$ que não o fizeram. A entrega da sacola foi feita pontualmente por $53,33 \%$ das famílias na primeira vez e por $40 \%$, na segunda. Já a entrega da sacola posterior a data estabelecida ocorreu em $46,60 \%$, na primeira vez, e $60 \%$, na segunda.

Ao nos voltarmos para os registros advindos das três ações, podemos perceber que alcançamos o objetivo de permitir a interação entre as crianças e os livros, pois isso se deu ao longo das intervenções literárias em sala de aula, das contações e do contato com o acervo do cantinho. E, segundo as famílias, também ocorreu na realização da atividade proposta pela Sacola Viajante. Mesmo que em alguns momentos da interação tenha havido disputas pelos livros, durante a contação e principalmente no acesso ao acervo do cantinho do Era uma vez..., notamos que as crianças buscavam compartilhar as informações obtidas a partir do contato com o livro, apontando para as ilustrações, contando aos colegas, às professoras, aos pais e até para os bonecos e/ou bichos de pelúcia. Oliveira et al. (2012) alega que essa interação é crucial para a aprendizagem pueril e entendemos que as propiciadas pelo livro foram igualmente importantes. Bettelheim (2014) argumenta sobre a importância de alimentarmos o imaginário infantil e concordamos com essa ideia, julgando que as práticas desenvolvidas com o livro nas turmas do berçário foram válidas para o estímulo à imaginação dos pequenos. Tal fato era traduzido na necessidade de compartilhar o que liam, de contar aos outros, de enriquecer e dar sua versão.

Os comportamentos dos pequenos nos levam a considerar que os projetos foram significativos para construir e reforçar o vínculo com os livros, com professoras e mediadoras daquelas situações de sala de aula, com os colegas e também com as famílias. Isso ilustra a fala de Mir (2004), quando se refere a ser nato às crianças a exploração visual e tátil dos objetos e que tal ação contribui para o seu desenvolvimento cognitivo e afetivo. Verificamos isso ao observar as imagens e os registros dos pais: pequenos manuseando, simulando a leitura, olhando atentamente para os livros, apontando e reconhecendo as imagens que Ihes eram familiares, tentando mostrar e contar histórias para os seus brinquedos ou animais de pelúcia.

Sabemos que os livros infantis precisam confirmar aquilo que a criança já conhece, mas também desafiá-la e apresentá-la a novas realidades. Em vista disso acreditamos, no que se refere às obras selecionadas, que elas conseguiram proporcionar aos alunos esse contato com histórias que Ihes eram familiares, provocando 0 reconhecimento assim como a inquietação com o desconhecido. O acervo selecionado para os três projetos não era voltado à pedagogização, mas à representação das experiências infantis, visando proporcionar uma leitura descompromissada, feita por prazer e para construir significados, ou seja, sem a pressão de confeccionar trabalhos a partir dela, portanto a leitura não era concebida como pano de 
fundo, mas sim como parte fundamental da rotina escolar.

O conteúdo das narrativas e poesias, por sua vez, mobilizou reações múltiplas, como trocas afetivas e diálogos espontâneos com os colegas e professoras, e igualmente com as famílias durante 0 Sacola Viajante. Além da construção de novos saberes, ouvir histórias possibilitou que houvesse trocas afetivas e manifestações de sentimentos. No que tange ao suporte, foram escolhidos livros de diferentes materiais e formatos, bem como gêneros diversos. Além disso, proporcionamos que os pequenos ouvissem tais histórias através de diferentes recursos visuais, como fantoches, dedoches, avental de contação, teatro, vídeo, entre outros. Isso despertou a atenção e a curiosidade e também possibilitou que eles explorassem de forma tátil os elementos presentes nas narrativas e poemas. Logo, eles já tinham adotado postura frente às narrativas, demonstrando suas preferências e desagrados, posto isso, entendemos que desde esse momento já se configurava um comportamento leitor.

Diante desse fato, por se tratarem de crianças bem pequenas, a presença de um mediador foi indispensável, não só nas atividades com o livro, mas em todas as práticas aplicadas ao berçário. Ele precisa ser sensível ao fazer a seleção das obras, reconhecendo as especificidades do público e, por vezes, alterando o planejamento. Debus (2006), nesse sentido, salienta a importância que o professor promotor de práticas de leitura possui na inserção do aluno no mundo letrado.

Já no que tange ao envolvimento familiar, observamos que a maior participação aconteceu na primeira rodada devido ao fato de esses pais estarem tendo seu primeiro contato com as atividades escolares dos filhos, o que nos leva a presumir que havia uma empolgação e sensação de novidade. Um dado que nos surpreendeu foi a participação de alguns dos irmãos dos nossos alunos. Essas crianças, todas mais velhas, entre quatro a sete anos, envolveram-se com a contação, seja narrando as histórias ou ouvindo-as junto com os irmãos mais novos. Portanto, um de nossos objetivos com esse projeto, que era proporcionar que a família mediasse e se reunisse para contar histórias, foi atingido, pois segundo a maioria dos relatos dos pais houve esse momento para reunir a família em torno do livro.

Algumas famílias também relataram que o contato com as obras enviadas, tanto na primeira como na segunda rodada, aconteciam por mais de uma vez, o que nos leva a supor que as crianças solicitavam essa releitura em outras oportunidades, uma vez que em sala de aula, ao final das contações, eles pediam que contassem de novo ou que permitissem explorar mais o livro. Tal dado nos faz pensar que as obras despertavam a curiosidade dos alunos para além do momento da contação. Embora cada criança tenha recebido a Sacola Viajante apenas em duas oportunidades, a ação permitiu que fossem estimuladas as interações familiares a partir e em torno do objeto livro.

\section{Conclusão}

Para formar leitores na tenra infância são necessárias ações sistemáticas de leitura que sejam propiciadas pela escola, estendidas e continuadas pela família. Essas práticas devem ter prosseguimento ao longo da vida escolar da criança para que ela se torne leitora e aperfeiçoe a sua formação como tal. Do mesmo modo, é necessário estarem inseridas em um ambiente familiar que favoreça essa constituição. Portanto, além do comprometimento da escola em promover projetos e atividades que englobem a leitura literária, é necessário que o professor de turmas da Educação Infantil se comprometa em desenvolver e ampliar o contato entre alunos e livros. Junto a isso, o envolvimento e a participação familiar são imprescindíveis. Infelizmente, nem sempre os alunos que participaram dos projetos tiveram esse acompanhamento e mediação familiar presentes, fato que pode influenciar nessa caminhada rumo a sua formação leitora.

Os três projetos aplicados foram desenvolvidos especificamente para o berçário pelas professoras, não havia nenhuma ação da escola para formar leitores nessas turmas, mas a instituição se mostrou 
receptiva e permitiu que os projetos acontecessem. Acreditamos que, em determinados momentos, as turmas de bebês e crianças pequenas são subestimadas, pois se acredita que tais crianças não são aptas a participarem de ações que envolvam o livro. Percebemos isso pela forma com que outras professoras da escola concebiam essa relação entre os pequenos e os livros, pensando que eles não tinham "maturidade para ouvir histórias" ou reduzindo o trabalho que era feito a apenas "mexer nos livrinhos". No entanto, sabemos que é pertinente inserir a leitura literária desde a tenra infância, tendo em vista os consideráveis benefícios que ela propicia aos infantes, como o desenvolvimento do imaginário, o envolvimento, a participação, a construção de aprendizados de forma lúdica, a descoberta e a aquisição de novas palavras, a ampliação do vocabulário, além de contribuir para uma futura alfabetização.

Essa pesquisa nos revelou que as práticas de leitura que visam à formação de leitores precisam acontecer de forma sistemática, que essas ações devem ter continuidade e simultaneidade, isto é, que tenham uma sequência bem delineada de atividades e que essas sejam estendidas para além da escola. Além disso, o planejamento, a mediação entre as crianças e os livros, a criação de um espaço acessível aos petizes na sala de aula para acolher o acervo, bem como a delimitação de um lugar para que as obras sejam exploradas foram fatores decisivos para a formação leitora dos alunos do berçário. Logo, esse aspecto que combina planejamento e espaço adequado é significativo para que projetos de leitura literária sejam ações bemsucedidas.

As transformações de comportamento dos alunos em relação aos livros ocorreram de forma gradativa: observamos a constituição da autonomia na exploração das obras, a maior participação, organização e concentração no momento de ouvir e manusear o acervo, a demarcação de um lugar na sala de aula para ler, a simulação de leitura, a necessidade de compartilhar o que liam e também o fato de trazerem livros de casa. É evidente que para tais alterações comportamentais foi necessária a mediação constante, a presença diária das práticas de leitura, assim como a criação de um espaço dedicado para a leitura e exploração do livro na rotina dos alunos para que, como consequência dessas ações, se constituíssem comportamentos leitores. Logo, é possível afirmar que, sim, os projetos de leitura literária aplicados a turmas de berçário permitem a interação com os livros e contribuem para a formação de hábitos leitores.

Enquanto pesquisadoras, esperamos colaborar com a discussão que nos faz pensar sobre a leitura literária e a formação de leitores na Educação Infantil, em específico no berçário, uma vez que há uma ausência de estudos nessa área. As atividades fizeram com que os alunos se engajassem nas situações apresentadas, despertando a curiosidade para aquilo que até então era novo e desconhecido e mobilizando reações espontâneas e ímpares. Em vista disso, as ações reafirmam o espaço que a leitura literária precisa possuir na sala de aula de bebês e crianças bem pequenas, espaço esse que, se ampliado para o ambiente familiar, pode se traduzir na adoção de comportamentos perenes de leitura.

\section{Referências}

BETTELHEIM, Bruno. A psicanálise dos contos de fadas. 35. ed. Rio de Janeiro: Paz e Terra, 2014. $448 \mathrm{p}$.

BORDINI, Maria da Glória. Poesia e consciência linguística na infância. 2. ed. In: SMOLKA, Ana Luiza B et al. Leitura e desenvolvimento da linguagem. São Paulo: Global, 2010. 112 p.

BRASIL. Ministério da Educação. Lei de Diretrizes e Bases da Educação Nacional (LDB). Lei Federal n. $=$ 9.394, de 26/12/1996. Disponível em: <http://www.planalto.gov.br/ccivil 03/Leis/L9394.ht $\mathrm{m}>$. Acesso em 25 de abril de $20 \overline{1} 7$.

DEBUS, Eliane. Festaria de brincança: a leitura literária na Educação Infantil. 1. ed. São Paulo: Paulus, 2006. $136 \mathrm{p}$.

HUNT, Peter. Crítica, teoria e literatura infantil. 1. ed. São Paulo: Cosac Naify, 2010. 316 p.

MIR, Maria Gloria Medrano. A criança e seu crescimento: aspectos motores, intelectuais, 
afetivos e sociais. 5. ed. In: ARRIBAS, Teresa Lleixà et al. Educação infantil: desenvolvimento, currículo e organização escolar. Porto Alegre: Artmed, 2004. 395 p.

OLIVEIRA, Zilma Ramos de et al. O trabalho do professor na Educação Infantil. 1. ed. São Paulo: Biruta, 2012. 420 p.

VIGOTSKI, Lev Semenovitch. Imaginação e criatividade na infância. 1. ed. Tradução: João Pedro Fróis. São Paulo: WMF Martins Fontes, 2014. 144 p.

\section{COMO CITAR ESSE ARTIGO}

MELO, Caroline Rodrigues; RÊGO, Zila Letícia Pereira. E agora, minha gente, uma história eu vou contar: experiências de formação de leitores no berçário. Signo, Santa Cruz do Sul, v. 43, n. 78, nov. 2018. ISSN 19822014. Disponível em: <https://online.unisc.br/seer/index.php/signo/article/view/12036>. Acesso em: . doi: https://doi.org/10.17058/signo.v43i78.12036. 